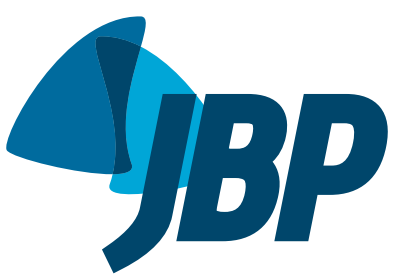

1. Departamento de Medicina Clínica, Universidade Federal do Ceará, Fortaleza (CE) Brasil.

2. Programa de Pós-Graduação de Mestrado em Ciências Médicas, Universidade Federal do Ceará, Fortaleza (CE) Brasil.

3. Divisão de Pneumologia, Instituto do Coração, Hospital das Clínicas, Faculdade de Medicina, Universidade de São Paulo, São Paulo (SP) Brasil.

4. Faculdade de Medicina, Escola Paulista de Medicina, Universidade Federal de São Paulo, São Paulo (SP) Brasil.

a. (ID) http://orcid.org/0000-0002-6002-0084

b. (iD http://orcid.org/0000-0001-6845-7398

c. (iD http://orcid.org/0000-0001-6548-1384

d. (iD http://orcid.org/0000-0002-5288-3533

Submitted: 30 May 2017

Accepted: 3 September 2017.

Study carried out in the Departamento de Medicina Clínica, Universidade Federal do Ceará, Fortaleza (CE) Brasil.

\section{Patient-ventilator asynchrony}

\author{
Marcelo Alcantara Holanda ${ }^{1,2, a}$, Renata dos Santos Vasconcelos ${ }^{2, b}$ \\ Juliana Carvalho Ferreira ${ }^{3, c}$, Bruno Valle Pinheiro ${ }^{4, c}$
}

\begin{abstract}
Patient-ventilator asynchrony (PVA) is a mismatch between the patient, regarding time flow, volume, or pressure demands of the patient respiratory system, and the ventilator, which supplies such demands, during mechanical ventilation (MV). It is a common phenomenon, with incidence rates ranging from 10\% to $85 \%$. PVA might be due to factors related to the patient, to the ventilator, or both. The most common PVA types are those related to triggering, such as ineffective effort, auto-triggering, and double triggering; those related to premature or delayed cycling; and those related to insufficient or excessive flow. Each of these types can be detected by visual inspection of volume, flow, and pressure waveforms on the mechanical ventilator display. Specific ventilatory strategies can be used in combination with clinical management, such as controlling patient pain, anxiety, fever, etc. Deep sedation should be avoided whenever possible. PVA has been associated with unwanted outcomes, such as discomfort, dyspnea, worsening of pulmonary gas exchange, increased work of breathing, diaphragmatic injury, sleep impairment, and increased use of sedation or neuromuscular blockade, as well as increases in the duration of MV, weaning time, and mortality. Proportional assist ventilation and neurally adjusted ventilatory assist are modalities of partial ventilatory support that reduce PVA and have shown promise. This article reviews the literature on the types and causes of PVA, as well as the methods used in its evaluation, its potential implications in the recovery process of critically ill patients, and strategies for its resolution.
\end{abstract}

Keywords: Respiration, artificial; Respiratory insufficiency; Interactive ventilatory support.

\section{INTRODUCTION}

\section{Definition and epidemiology}

Mechanical ventilation (MV) is one of the most commonly used interventions in the ICU, being indispensable to maintaining the life of critically ill patients with acute respiratory failure. ${ }^{(1)}$ The main objectives of $\mathrm{MV}$ include maintaining adequate levels of gas exchange and decreasing respiratory effort, until the clinical condition that was the indication for MV is resolved or compensated. ${ }^{(2)}$ To that end, the goal should be optimal patient-ventilator interaction, with a balance between patient inspiratory effort and ventilator triggering, between ventilatory demand and delivery of flow and tidal volume, and between interruption of patient inspiration and cycling of the device. Patient-ventilator asynchrony can be defined as a mismatch between the patient, regarding time, flow, volume, or pressure demands of the patient respiratory system, and the ventilator, which supplies such demands, during MV. ${ }^{(3)}$ Asynchrony events can range from subtle changes, the detection of which demands strong suspicion and refined monitoring, to an evident "struggle" between the patient and the ventilator.

Patient-ventilator asynchrony has incidence rates ranging from $10 \%$ to $85 \%$. . $^{(-8)}$ This great variation can be explained by the fact that different factors affect the incidence and detection of patient-ventilator asynchrony (Chart 1). To quantify this phenomenon, some authors have proposed the asynchrony index (AI), defined as the number of asynchrony events divided by the total respiratory rate, that is, the sum of ventilator cycles and ineffective efforts, and expressed as a percentage. In one pioneering study, ${ }^{(5)}$ nearly one fourth of the patients had an AI above $10 \%$ when the incidence of events over only 30 min of continuous monitoring of intubated patients was evaluated.

\section{RISK FACTORS}

\section{Patient-related factors}

Regardless of the etiology of the respiratory failure leading to the need for MV, the greater clinical severity of the patient favors the occurrence of asynchrony, especially during the initial phases of ventilatory support. Sepsis, acidosis, anxiety, and fever are some of the factors that increase ventilatory demand and hinder the balance between the flow and volume demanded by the patient and those delivered by the ventilator, contributing to the occurrence of asynchrony. ${ }^{(9)}$ In patients who are unstable, sedation and analgesia are often required until stabilization is achieved. The underlying diagnosis is also very relevant. COPD has been considered the most commonly associated 
condition with asynchrony, especially in the presence of auto-positive end-expiratory pressure (auto-PEEP), which hinders ventilator triggering and favors the frequent occurrence of ineffective efforts. ${ }^{(10)}$ Respiratory mechanics influences the type of patient-ventilator asynchrony, depending on neural inspiratory time and on ventilator settings. ${ }^{(10,11)}$ An obstructive respiratory mechanics profile appears to be more associated with delayed cycling asynchrony, aggravated by short neural inspiratory time, whereas a restrictive respiratory mechanics profile with longer neural inspiratory time favors premature cycling events during pressure support ventilation (PSV) and proportional assist ventilation plus $(\mathrm{PAV}+){ }^{(11)}$ In fact, depending on the ventilatory mode, COPD patients can also have cycle asynchrony. This occurs, for instance, when patients receive PSV, whose cycling is linked to the percent reduction in inspiratory flow. ${ }^{(12,13)}$ Another condition that favors certain types of asynchrony is acute respiratory distress syndrome (ARDS). Patients with this condition should be ventilated with low tidal volumes and low continuous positive airway pressures. (2) Although these settings are lung protective, they are often not tolerated by the patient and cause asynchrony. ${ }^{(14)}$ Double triggering is one the most common types of asynchrony and can result in the delivery of converging respiratory cycles, which means that MV is no longer protective. This hypothesis has been proposed to explain the satisfactory results with the use of neuromuscular blockade in the first days of ventilation in patients with severe ARDS, perhaps because it prevents this type of asynchrony and ensures protective ventilation. ${ }^{(15)}$

\section{Ventilator-related factors}

The choice of ventilatory mode and the choice of ventilator settings are factors that affect the incidence of asynchrony. A study involving 62 patients, 11 on volume-controlled ventilation (VCV) and 51 on PSV, detected 2.1 asynchrony events per minute, on average, the incidence being significantly higher in those on VCV than in those on PSV $(4.3 \pm 4.8$ events/ min vs. $1.9 \pm 3.8$ events/min). (5) In conventional modes-VCV, pressure-controlled ventilation (PCV), and PSV-pneumatic triggering can be a source of asynchrony, especially in patients on auto-PEEP, such as those with COPD. ${ }^{(16)}$ The VCV mode is more commonly associated with asynchrony resulting from inadequate flow or tidal volume, such as double triggering, given that these parameters are set by the operator and are not always adequate to the demand of the patient. ${ }^{(17)}$ Switching to modes in which the flow and volume vary in response to patient effort, such as PSV and PCV, can improve comfort. ${ }^{(18)}$ However, choosing a ventilatory mode that allows the patient to have a certain control over inspiratory flow, such as PCV or PSV, does not ensure optimal patient-ventilator interaction. For the application of PCV and PSV, the choice of the level of support to be delivered is essential and should be individualized.

\section{TYPES OF ASYNCHRONY, DIAGNOSES, AND STRATEGIES}

By analyzing volume, flow, and pressure waveforms on the mechanical ventilator display, it is possible to detect the most common types of patient-ventilator asynchrony, which are those related to triggering, those related to cycling, and those related to flow. Chart 2 presents the types of patient-ventilator asynchrony and comments on ventilator- and patient-related factors, as well as therapeutic strategies for each situation.

Triggering asynchronies include ineffective triggering or effort, auto-triggering, and double triggering. They are called so because they result from problems in the triggering or initiation of the respiratory cycle by the ventilator in response to patient respiratory muscle effort. Ineffective triggering consists in failure to recognize patient inspiratory muscle effort. Figure 1 illustrates two different scenarios in which ineffective efforts can occur. Ineffective efforts might be due to factors related to the ventilator, such as inappropriate sensitivity setting or malfunctioning sensitivity; to the patient, such as respiratory muscle weakness (whether or not it is related to sedation) or neuromuscular blockade (due to auto-PEEP); or to both. Clinically, patient inspiratory effort can be sensed by touching the chest or abdomen, observing that movement of the chest or abdomen is not accompanied by a ventilator-delivered breath. ${ }^{(2)}$

To resolve ineffective triggering, the sensitivity should be set as high as possible, thus avoiding, however, auto-triggering and switching from pressure triggering to flow triggering, which is more sensitive. When auto-PEEP associated with dynamic hyperinflation is observed, one can attempt to increase PEEP cautiously-monitoring the resolution or attenuation of asynchrony, rarely exceeding $10 \mathrm{cmH}_{2} \mathrm{O}$, or reducing the pressure support

Chart 1. Factors that affect the occurrence and detection of patient-ventilator asynchrony.

Factors related to the occurrence of asynchrony Indication for MV

Severity of respiratory failure Ventilatory modes

Ventilator settings

Level of sedation
Factors related to the detection of asynchrony Observation time

Length of the observation periods

Timing of observation during MV (e.g., first days and phase of weaning)

Detection method (e.g., clinical assessment, waveform monitoring, esophageal balloon measurement, and detection of the electrical activity of the diaphragm) Definition of asynchrony and of its significance

MV: mechanical ventilation. 
Chart 2. Common types of patient-ventilator asynchrony, associated factors, and therapeutic strategies.

\begin{tabular}{|c|c|c|}
\hline Asynchrony & Determining factors & Therapeutic strategies \\
\hline \multicolumn{3}{|l|}{ Triggering } \\
\hline \multirow[t]{6}{*}{ Ineffective triggering } & Ventilator: & \\
\hline & $\begin{array}{l}\text { Inappropriate sensitivity setting or } \\
\text { malfunction of the sensitivity mechanism }\end{array}$ & $\begin{array}{l}\text { Adjustment/correction of sensitivity problems } \\
\text { (flow more sensitive than pressure) }\end{array}$ \\
\hline & Prolonged inspiratory time & $\begin{array}{l}\text { Decrease inspiratory time by adjusting settings } \\
\text { for each mode (VCV, PCV, and PSV) }\end{array}$ \\
\hline & Patient: & \\
\hline & $\begin{array}{l}\text { Respiratory muscle weakness } \\
\text { Decreased neural drive }\end{array}$ & $\begin{array}{l}\text { Reduce or discontinue neural drive depressants, } \\
\text { sedation, or NMBA }\end{array}$ \\
\hline & Dynamic hyperinflation (auto-PEEP) & $\begin{array}{l}\text { Minimize hyperinflation and titrate extrinsic } \\
\text { PEEP (values lower than auto-PEEP values), } \\
\text { decrease PS levels (PSV mode) }\end{array}$ \\
\hline \multirow[t]{3}{*}{ Double triggering } & Ventilator: & \\
\hline & $\begin{array}{l}\text { Inspiratory time too short relative to neural } \\
\text { inspiratory time }\end{array}$ & $\begin{array}{l}\text { Increase inspiratory time (VCV or PCV) or } \\
\text { decrease the cycling threshold percentage of } \\
\text { peak flow (PSV) }\end{array}$ \\
\hline & Low tidal volume in VCV & $\begin{array}{l}\text { Deep sedation } \pm \text { NMBA in early severe ARDS } \\
\text { Modes that allow variation in tidal volume, } \\
\text { such as PCV }\end{array}$ \\
\hline Reverse triggering & $\begin{array}{l}\text { Muscle effort resulting from mechanical } \\
\text { inflation }\end{array}$ & Reduce sedation, NMBA in early severe ARDS \\
\hline \multirow[t]{5}{*}{ Auto-triggering } & Ventilator: & \\
\hline & "Excessive" sensitivity & Optimize the sensitivity setting \\
\hline & System leak & Correct leak \\
\hline & $\begin{array}{l}\text { Condensate in the ventilator circuit } \\
\text { Patient: }\end{array}$ & Remove condensate \\
\hline & $\begin{array}{l}\text { Transmission of pressure or flow oscillations } \\
\text { because of cardiac activity }\end{array}$ & Optimize the sensitivity setting \\
\hline \multicolumn{3}{|l|}{ Cycling } \\
\hline \multirow[t]{4}{*}{ Premature cycling } & Ventilator: & \\
\hline & $\begin{array}{l}\text { Inspiratory time is too short relative to } \\
\text { patient inspiratory time }\end{array}$ & $\begin{array}{l}\text { In VCV, decrease inspiratory flow or increase } \\
\text { tidal volume } \\
\text { In PCV, increase inspiratory time }\end{array}$ \\
\hline & Patient: & \\
\hline & $\begin{array}{l}\text { Restrictive respiratory mechanics in PSV, as } \\
\text { in pulmonary fibrosis }\end{array}$ & $\begin{array}{l}\text { In PSV, decrease the cycling threshold } \\
\text { percentage criterion or increase PS }\end{array}$ \\
\hline \multirow[t]{4}{*}{ Delayed cycling } & Ventilator: & \\
\hline & $\begin{array}{l}\text { Inspiratory time is too long relative to } \\
\text { patient inspiratory time }\end{array}$ & $\begin{array}{l}\text { In VCV, increase inspiratory flow } \\
\text { In PCV, decrease inspiratory time }\end{array}$ \\
\hline & Patient: & \\
\hline & $\begin{array}{l}\text { Obstructive respiratory mechanics in PSV, } \\
\text { as in COPD }\end{array}$ & $\begin{array}{l}\text { In PSV, increase the cycling threshold } \\
\text { percentage criterion, or decrease PS, or } \\
\text { decrease rise time }\end{array}$ \\
\hline \multicolumn{3}{|l|}{ Flow } \\
\hline \multirow[t]{5}{*}{ Insufficient flow } & Ventilator: & \\
\hline & In VCV, the flow setting is too low & In VCV, increase inspiratory flow or switch to \\
\hline & $\begin{array}{l}\text { In PCV and PSV, the applied pressure is too } \\
\text { low, long rise time }\end{array}$ & PCV or PSV (free flow) \\
\hline & Patient: & \\
\hline & $\begin{array}{l}\text { Excessive ventilatory demand, increased } \\
\text { neural drive }\end{array}$ & $\begin{array}{l}\text { Reduce neural drive and metabolic demand: } \\
\text { control fever, pain, metabolic acidosis, and anxiety }\end{array}$ \\
\hline \multirow[t]{3}{*}{ Excessive flow } & Ventilator: & \\
\hline & In VCV, the flow setting is too high & In VCV, decrease inspiratory flow \\
\hline & $\begin{array}{l}\text { In PCV and PSV, the applied pressure is too } \\
\text { high, rise time is too short (overshoot) }\end{array}$ & $\begin{array}{l}\text { In PCV and PSV, decrease applied pressure, } \\
\text { increase rise time }\end{array}$ \\
\hline
\end{tabular}

VCV: volume-controlled ventilation; PCV: pressure-controlled ventilation; PSV: pressure support ventilation; NMBA: neuromuscular blocking agent; (auto-)PEEP: (auto-)positive end-expiratory pressure; PS: pressure support; and ARDS: acute respiratory distress syndrome. 

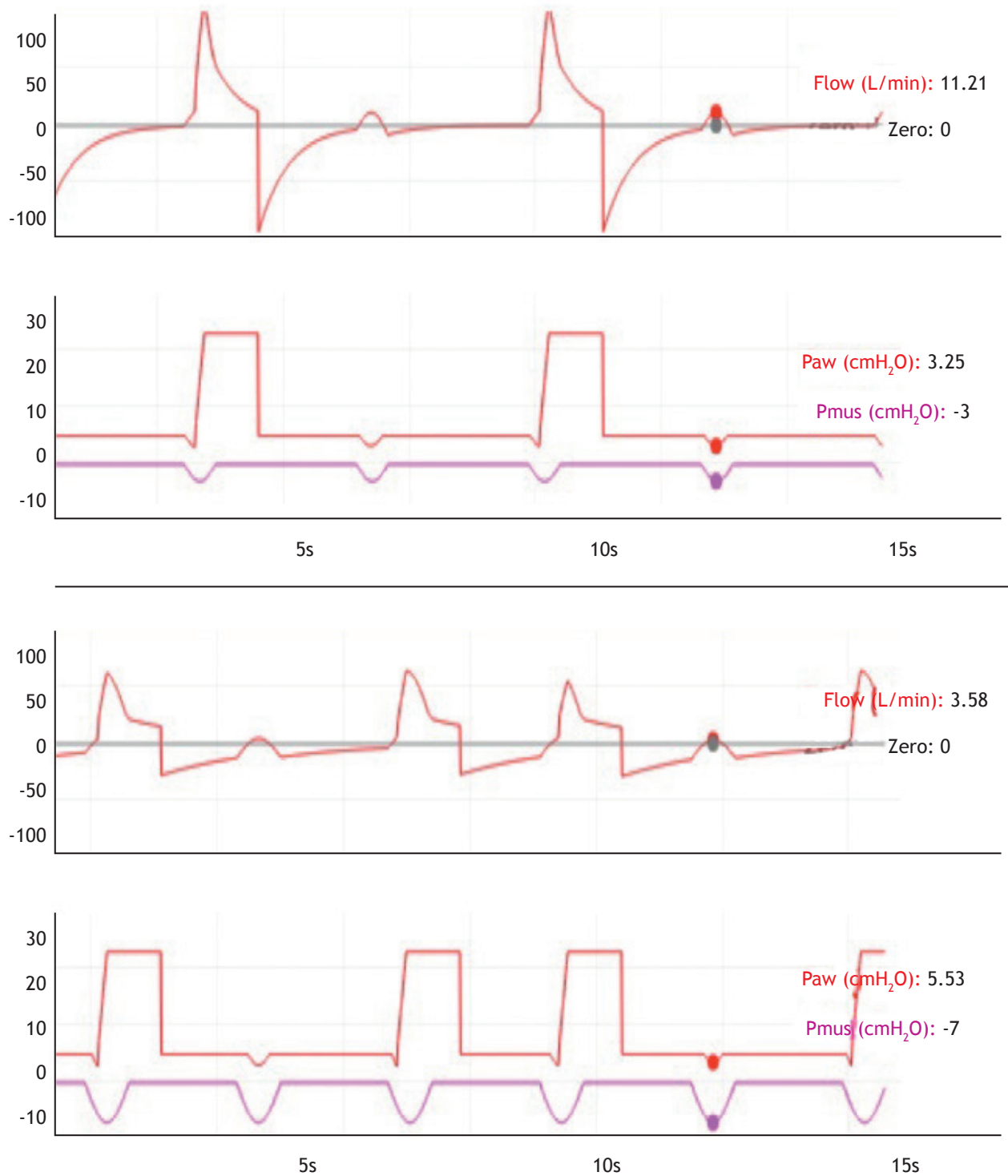

Figure 1. Flow and pressure waveforms, respectively, illustrating two simulated types of ineffective triggering. The first two waveforms represent a patient without problems in respiratory mechanics, with a weak spontaneous effort (Pmus) because of respiratory muscle weakness or decreased neural drive. The bottom two waveforms represent a patient with airflow obstruction and difficulty in triggering some breaths because of the presence of auto-positive endexpiratory pressure, even with a muscle effort that is "physiological" but unable to trigger ventilator breaths. In both cases, pressure-controlled ventilation (pressure sensitivity of $-2 \mathrm{cmH}_{2} \mathrm{O}$ ) was used. The dots on the waveforms indicate ineffective efforts. Paw: airway pressure; and Pmus: muscle pressure. Source: Xlung ${ }^{\circledR}$.

level in PCV and PSV (if tidal volume is high)-or to decrease inspiratory time in VCV.

Auto-triggering is the opposite of ineffective triggering: the ventilator triggers a breath when it improperly recognizes a flow or pressure variation in the circuit as being patient spontaneous respiratory muscle effort. In other words, the ventilator sensitivity system is "tricked" by artifacts, such as leaks with depressurization of the circuit or flow or pressure oscillations due to the presence of condensate in the circuit, or by transmission of intrathoracic pressure variations because of cardiac activity due to systolic ejection. Figure 2 illustrates two common situations that generate auto-triggering.

Double triggering consists of the ventilator delivering two consecutive breaths in response to patient respiratory muscle effort, that is, it occurs when patient effort triggers two breaths in a row. In such cases, patient neural inspiratory time is longer than the ventilator inspiratory time. The first trigger is from patient effort.

Reverse triggering occurs when patient inspiratory muscle effort results from reflex mechanisms triggered by mechanical insufflation with a ventilator-controlled 
breath. This form of patient-ventilator interaction, which is still unclear and potentially common, may go unnoticed clinically; it is necessary to monitor esophageal pressure, because the muscle effort does not originate in the respiratory center of the patient but rather in a patient-delivered breath. The term "entrainment" has also been used to describe this phenomenon. ${ }^{(19)}$ Figure 3 illustrates two types of asynchrony: double triggering and reverse triggering. In both cases, there is stacking of tidal volumes, resulting in distension of the lung parenchyma, with a corresponding increase in alveolar and airway pressures, and posing a risk of ventilator-induced lung injury, particularly in patients with ARDS. ${ }^{(2,17-19)}$ The main therapeutic strategy in such cases consists of increasing inspiratory time (in VCV and PCV), and, in PSV mode, it consists of increasing inspiratory time by decreasing the cycling percentage of peak flow.

Premature cycling occurs when the ventilator ends the inspiratory flow sooner than desired by the patient, that is, the ventilator inspiratory time is shorter than patient neural inspiratory time. Delayed cycling is due to the reverse: the ventilator delivers a breath with a longer inspiratory time than is desired by the patient, that is, the ventilator inspiratory time is longer than patient neural inspiratory time. In VCV and PCV, the ventilator operator
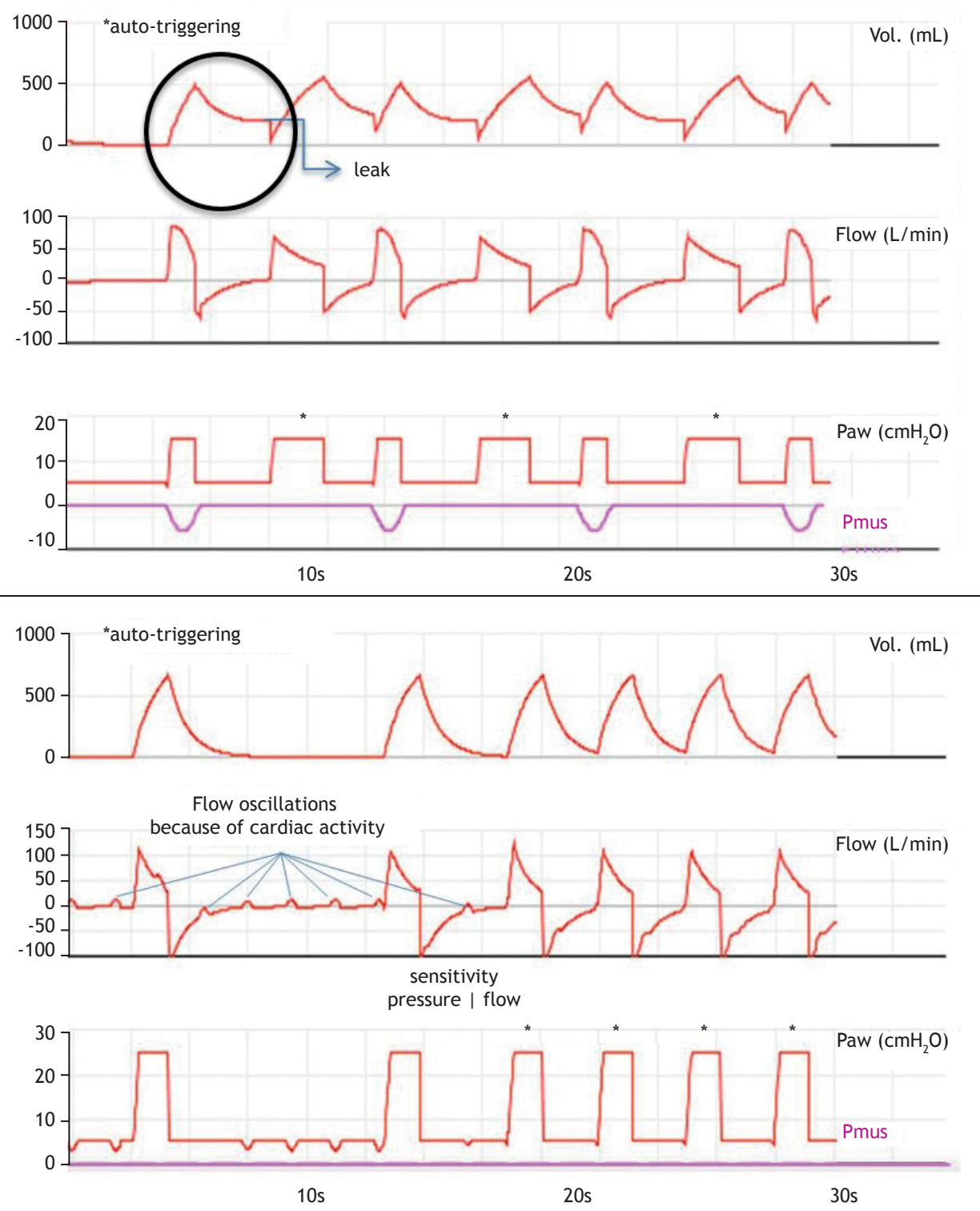

Figure 2. Volume, flow and pressure waveforms, respectively, illustrating two simulated types of auto-triggering. The first three waveforms represent a patient on pressure-support ventilation with flow sensitivity. The system with a leak causes the onset of flow-triggered breaths, without patient effort (Pmus $=0$ ). The bottom three waveforms represent a patient on pressure-controlled ventilation,* without respiratory muscle effort, but showing regular flow and pressure oscillations, with a respiratory rate of approximately 80 breaths/min, corresponding to his/her heart rate. Pressure sensitivity was changed to flow sensitivity. The increase in the total respiratory rate was due to triggers induced by transmission of flow oscillations because of cardiac activity. Vol.: volume; and Paw: airway pressure. Source: Xlung ${ }^{\circledR}$. 
can attempt to correct these asynchronies by directly adjusting the inspiratory time setting and assessing patient adaptation by interpreting the MV waveforms on the ventilator display. In PSV mode, the main strategy is to adjust the cycling threshold percentage of peak flow, which can usually be set between $5 \%$ and $70 \%$. To correct premature cycling, the threshold should be decreased, and, to correct delayed cycling, the threshold should be increased. In COPD patients, because of their increased airway resistance, the decrease in the flow delivered by PSV is slower, delaying ventilator cycling. This asynchrony can be corrected or minimized by adjusting the cycling level, which is usually preset at $25 \%$, to higher values, such as $40-50 \%$. Another approach can be to change the applied pressure support over PEEP. When this parameter is increased, inspiratory time usually increases as well, and vice-versa. Figure 4 illustrates premature cycling and delayed cycling, as well as the effects that changes in the cycling criterion have on these asynchronies.

Flow asynchrony can be of two types: insufficient inspiratory flow and excessive inspiratory flow. In instances of the first type, the flow received by the patient is lower than his/her ventilatory demand, typically occurring when the flow is set by the operator and cannot be increased by patient spontaneous
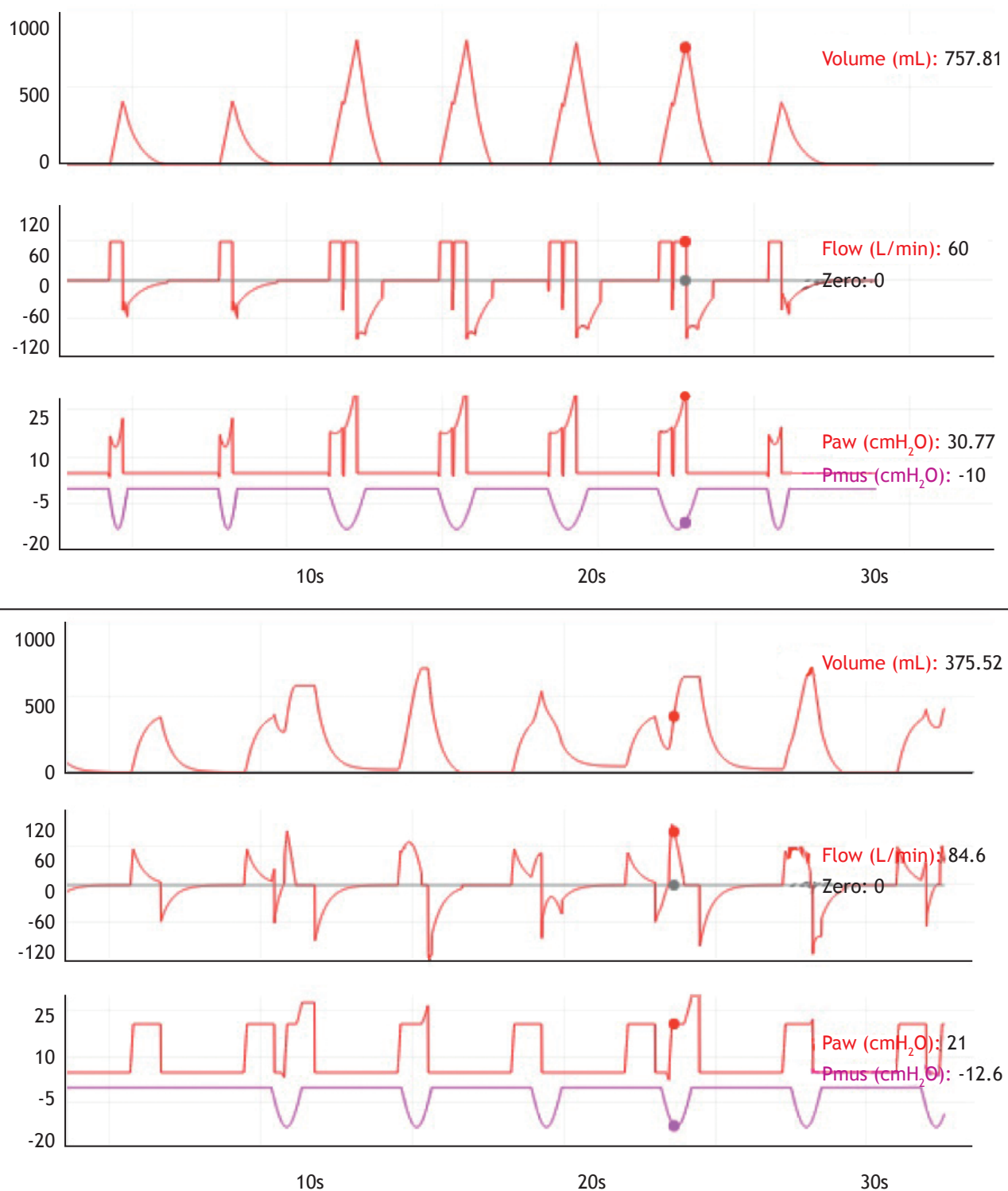

Figure 3. Volume, flow, and pressure waveforms, respectively, illustrating two simulations of asynchrony. The first three waveforms represent a case in which, because of patient neural inspiratory time, which is longer than the ventilator inspiratory time, the first breath is always triggered by the patient, during volume-controlled ventilation. The dots indicate stacked tidal volume caused by double triggering. The bottom three waveforms represent a case of reverse triggering due to respiratory muscle effort triggered by reflex mechanisms resulting from a ventilator-delivered breath, during pressure-controlled ventilation. Note, in both cases, stacked tidal volume and increased airway pressure during asynchrony. The dots indicate reverse triggering. Paw: airway pressure; and Pmus: muscle pressure. Source: Xlung ${ }^{\circledR}$. 
efforts, as occurs during VCV. However, insufficient inspiratory flow can also occur during PCV and PSV when the levels set are insufficient to deliver the flow "desired" by the patient. The therapeutic approach can include a reduction in ventilatory demand: correction of fever, anxiety, pain, acidosis, etc.; or an increase in flow delivery by means of appropriate adjustments for each mode (Chart 2), observing patient comfort and use of accessory respiratory muscles, as well as the conformation of the pressure waveform. In patients on VCV, switching to PCV or PSV, which have free flow, can be a good alternative. In addition, in PCV and PSV, an adjustment in rise time directly affects flow delivery soon after the respiratory cycle is triggered; the shorter the rise time, the higher the flow delivery and the faster the initial pressurization of the system; a short rise time is recommended in patients with clinical signs of air hunger. Excessive flow asynchrony occurs because of an exaggerated delivery of inspiratory flow. In some cases, excessive pressurization may occur, characterizing an overshoot of the flow in PCV or PSV. The best option consists of reducing flow delivery by reducing the set value in VCV or by reducing the applied pressure over PEEP or increasing the rise time in PCV and PSV. Figure 5 illustrates flow asynchrony and volume asynchrony during VCV, as well as their correction during PCV.

\section{ADVERSE EFFECTS OF PATIENT- VENTILATOR ASYNCHRONY}

\section{General}

Patient-ventilator asynchrony causes a series of adverse clinical effects and is associated with unwanted
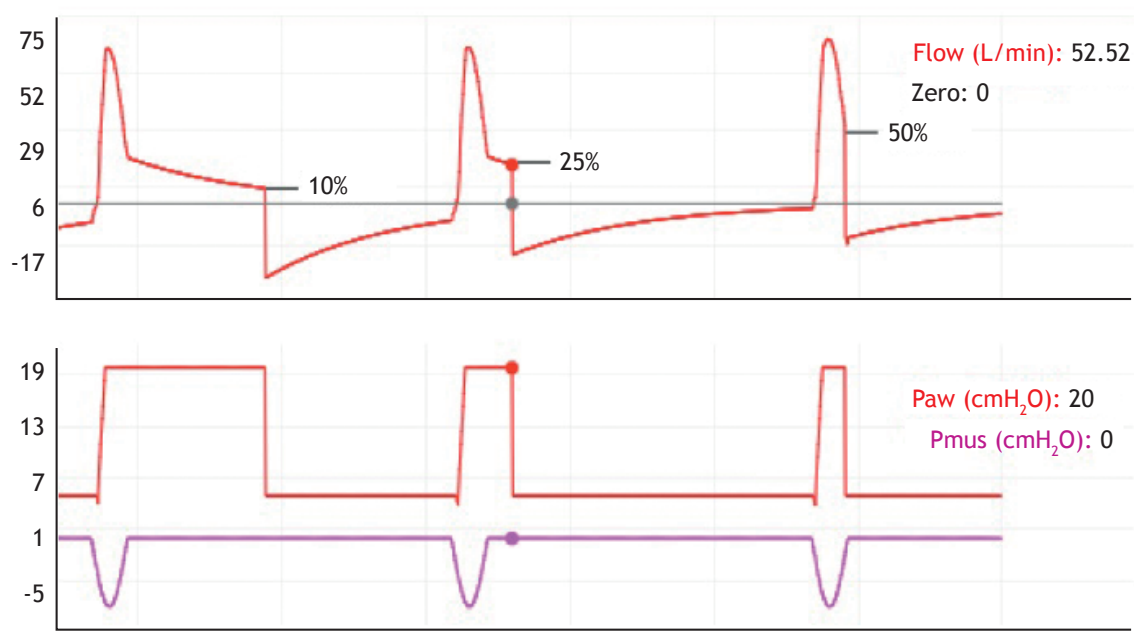

5s

$10 \mathrm{~s}$

$15 s$
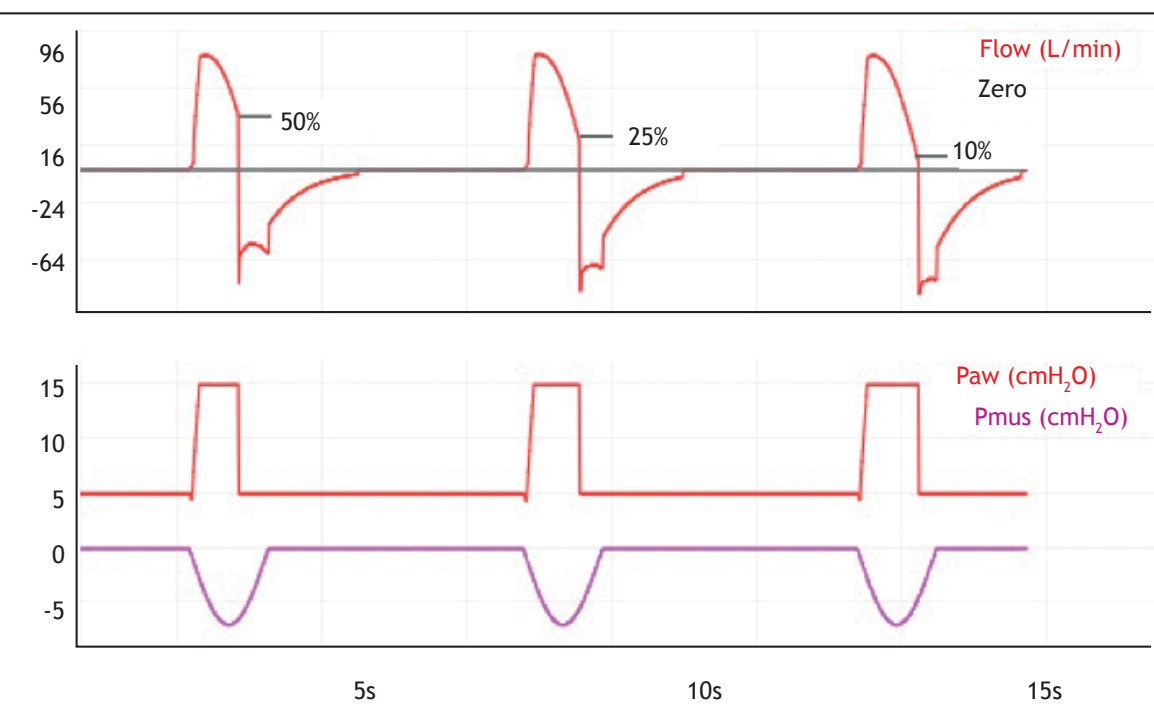

Figure 4. Flow and pressure waveforms, respectively, illustrating two types of cycling asynchrony simulated during pressure support ventilation. The first two waveforms represent a patient with COPD. Asynchrony is corrected by increasing the threshold percentage of peak inspiratory flow for termination of inspiration. The bottom two waveforms represent a patient with restrictive lung disease experiencing premature cycling. Asynchrony is attenuated by decreasing the cycling threshold percentage of peak flow. The dots indicate cycling during pressure support ventilation. Paw: airway pressure; and Pmus: muscle pressure. Source: Xlung ${ }^{\circledR}$. 
outcomes, such as discomfort, dyspnea, worsening of pulmonary gas exchange, increased respiratory effort, diaphragmatic injury, decreased quantity and quality of sleep, increased use of sedation, increased use of neuromuscular blockade, an increased duration of MV, and increased mortality. (20-23) Symptoms of "air hunger" or "excessive inspiratory effort", that is, dyspnea, although rarely studied, are very common during MV. In one study, the use of VCV was associated with these symptoms (OR $=4.77 ; 95 \% \mathrm{CI}: 1.6-4.3)$, and an increase in flow or tidal volume attenuated them in 10 of 45 patients (22\%). ${ }^{(24)}$ Not surprisingly, because VCV has stricter settings for delivery of flow and tidal volume, it is associated with greater discomfort in non-sedated patients, which could also be reflected in the incidence of asynchrony, although this last observation requires further evidence. ${ }^{24,25)}$ Asynchrony events can impair oxygenation. A decrease in AI-from 3.36\% during PSV to $1.73 \%$ during neurally adjusted ventilatory assist (NAVA)-was associated with an increase in the $\mathrm{PaO}_{2} / \mathrm{FiO}_{2}$ ratio $\left(203 \mathrm{mmHg}\right.$ vs. $254 \mathrm{mmHg}$ ). ${ }^{(26)}$ Both excessive and insufficient ventilatory support can cause respiratory muscle damage. In instances of the former, damage includes muscle fiber atrophy or apoptosis, and, in instances of the latter, damage includes increased work of breathing and eventually fatigue. Optimal patient-ventilator interaction, without asynchrony, would theoretically be ideal for the respiratory muscles. It is also possible that certain types of asynchrony, such as ineffective effort, especially when it occurs in the mid-expiratory phase, cause damage to diaphragm muscle fibers by generating eccentric or plyometric contractions during stretching of these fibers in this phase of the respiratory cycle. $(27,28)$

\section{Use of sedation}

Patients on MV are commonly sedated so that they can adapt to ventilatory support. ${ }^{(29)}$ However, observational studies have shown an association between deep sedation and a higher incidence of asynchrony. ${ }^{(22,30)}$ In one study, adult patients receiving PSV during deep sedation with propofol during wakefulness had, under sedation, a higher rate of asynchrony ( $21.8 \%$ vs. $5.9 \%)$; decreased respiratory drive, as measured by electrical activity of the diaphragm (Edi; $9.9 \mu \mathrm{V}$ vs. $3.1 \mu \mathrm{V}$ ); worsening of pulmonary gas exchange (increased $\mathrm{PaCO}_{2}$ ); and reduced tidal volume $(0.39 \mathrm{~L}$ vs. $0.44 \mathrm{~L}) .^{(31)}$ Deep sedation is currently considered a predictor of ineffective effort asynchrony. ${ }^{(29,32)}$ In addition to sedation level, drug type is a factor that affects the incidence of asynchrony. In a multicenter study, AI was lower when using dexmedetomidine as a sedative during MV compared with propofol (2.68\% vs. 9.10\%), even when targeting light sedation. ${ }^{(33)}$ Increasing intravenous sedation to reduce asynchrony appears to be an ineffective, if not harmful, strategy. Ventilator adjustments, such as changing the ventilatory mode or increasing inspiratory time to one second, were more effective in reducing asynchrony than was increasing sedation. ${ }^{(34)}$ Therefore, in patients experiencing asynchrony, continuous intravenous sedation should only be instituted or increased after optimization of ventilator settings combined with management of common clinical problems, such as pain, anxiety, and delirium, or with prompt administration of a bolus in cases of an evident "struggle" between the patient and the ventilator, for safety reasons.
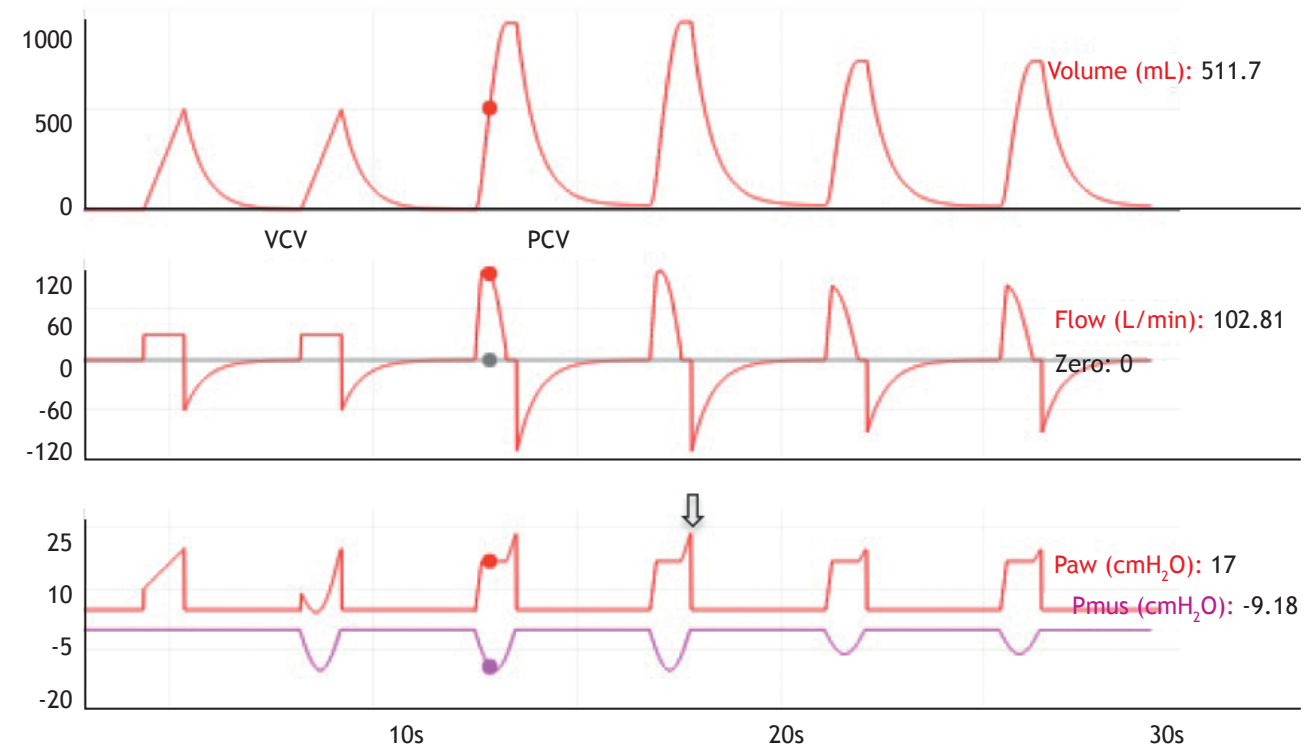

Figure 5. Volume, flow, and pressure waveforms, respectively, illustrating simulation of correction of flow asynchrony and volume asynchrony (air hunger), evident in the second breath, during VCV. The application of PCV from the third breath onward enabled delivery of flow and tidal volume. The patient responded with decreased muscle contraction (Pmus) from the fourth breath onward. Note a slight airway pressure overshoot at the end of breath during PCV (arrow), attenuated by better adaptation of the patient. The dots indicate free-flow delivery during PCV. VCV: volume-controlled ventilation; PCV: pressure-controlled ventilation; Paw: airway pressure;; and Pmus: muscle pressure. Source: Xlung ${ }^{\circledR}$. 


\section{Sleep impairment}

ICU patients on MV are highly susceptible to sleep fragmentation and decreased sleep time because of the presence of alarms, the use of inappropriate ventilator settings, and patient-ventilator asynchrony. ${ }^{(1,2)}$ However, the relationship between patient-ventilator asynchrony and sleep quality is controversial. (35-37) In one study, total sleep time and sleep efficiency were higher during MV than during spontaneous breathing in tracheostomized patients on prolonged MV. Some patients had respiratory events (central apnea and double triggering asynchrony) that accounted for $11 \%$ of the sleep fragmentation index during MV. It is possible that, once asynchrony has been corrected by making appropriate ventilator adjustments, there is even greater advantage in using MV than spontaneous breathing. ${ }^{(38)}$ One study compared PAV+ and PSV during sleep. ${ }^{(8)}$ Although there was a significant reduction of asynchrony events/h with PAV+ relative to PSV (5 events/h vs. 40 events/h), this effect did not lead to a significant improvement in sleep quality, and PAV+ was associated with increased sleep fragmentation (18.8 events/h vs. 18.1 events/h) and with a lower rapid-eye-movement sleep percentage $(0.0 \%$ vs. $5.8 \%) .{ }^{(8)}$ Current findings are insufficient to determine if, how, and the extent to which, patient-ventilator asynchrony affects sleep.

\section{Duration of $M V$ and mortality}

In a pioneering study, ${ }^{(4)}$ the presence of ineffective efforts, as detected over an observation period of only 2 min within the first week of admission to a weaning center, was identified in 19 of 174 patients (11\%). In this group of patients, this presence was associated with a lower rate of weaning success ( $16 \%$ vs. $57 \%$ ). Patients in this group were older, were more likely to have been diagnosed with COPD, had higher $\mathrm{PaCO}_{2}$, and had lower MIP; it was not possible to confirm the relationship between patient-ventilator asynchrony and impaired weaning. ${ }^{(4)}$ In another study, ${ }^{(5)}$ it was observed that patients with an $\mathrm{AI} \geq 10 \%$, as determined over a 30-min observation period aimed at detecting four types of asynchrony, had longer duration of MV than did those with an AI < 10\% ( 25 days vs. 7 days). Among the former, there was a higher proportion of patients who required tracheostomy (33\% vs. $4 \%$ ). Mortality in the $\geq 10 \%$ AI group was $47 \%$ vs. $32 \%$ in the $<10 \%$ AI group, a difference without statistical significance $(p=0.36)$. However, patients with patient-ventilator asynchrony had different clinical characteristics, a higher proportion of them having COPD, as well as higher bicarbonate and $\mathrm{pH}$ levels; a cause-and-effect relationship was not established between patientventilator asynchrony and impaired weaning. (5)

In another study, ${ }^{(32)} 60$ patients were evaluated over $20 \mathrm{~min}$ within the first $24 \mathrm{~h}$ of ventilatory support, regarding the occurrence of ineffective efforts. Fourteen patients (23\%) were identified as having an AI $\geq 10 \%$, all of whom had demographic and clinical characteristics similar to those of patients with an AI $<10 \%$. Compared with patients in the $<10 \%$ AI group, those in the $\geq 10 \%$ AI group had longer duration of MV ( 6 days vs. 2 days; $\mathrm{p}=0.007$ ), fewer ventilator-free days ( 21 days vs. 25 days; $p=0.02$ ), and longer ICU stays ( 8.3 days vs. 4.2 days; $p=0.01$ ). Mortality did not differ significantly between the groups (5.3 vs. 9.2\%; $p=0.39$ ). ${ }^{\text {(32) }}$ One of the major limitations of studies on the incidence of patient-ventilator asynchronies and their effects on clinical outcomes is the fact that the observation period is too short. To overcome this limitation, a group of researchers investigated patient-ventilator asynchrony through analysis of asynchronies detected by dedicated software throughout the period when a group of patients was on MV. ${ }^{(22)}$ The following types of asynchrony were monitored; ineffective efforts; double triggering; aborted inspirations; premature cycling; and delayed cycling. Of a total of 50 patients who remained on MV for more than $24 \mathrm{~h}$, those with an $\mathrm{AI} \geq 10 \%$ showed a tendency toward having longer duration of MV than did those with an $\mathrm{AI}<10 \%$ ( 16 days vs. 6 days; $p=0.061$ ). ICU mortality was significantly higher among the former than among the latter $(67 \%$ vs. $14 \% ; p=0.011)$, as was in-hospital mortality (67\% vs. $23 \%$; $p=0.044)$. The longer observation period, which is a major difference relative to other studies and covered more than $80 \%$ of the total duration of MV, was the strength of that study. ${ }^{(22)}$ This allowed the determination of the true incidence of patient-ventilator asynchrony and may have been the reason why an association was identified between this incidence and higher mortality. In contrast, the fact that patient-ventilator asynchronies were identified automatically through the use of dedicated software, which is not yet available for confirming these findings in other centers, constitutes a limitation; it should be highlighted that the association found between the incidence of patient-ventilator asynchrony and higher mortality does not definitively establish a causal relationship between patient-ventilator asynchrony and duration of MV or between patient-ventilator asynchrony and mortality. ${ }^{(22)}$

\section{PAV AND NAVA}

PAV and NAVA are two new ventilatory modes that have been developed to reduce the occurrence of

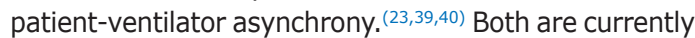
classified as proportional modes, because they require the patient to make some inspiratory effort and deliver partial support in proportion to patient effort. This is what mainly distinguishes these two modes from other pressure support modes, such as PSV, in which airway pressure is set and adjusted in the ventilator and is not changed by patient effort. In NAVA and PAV, although through different algorithms, airway pressure varies in proportion to patient effort: the greater the effort, the greater the inspiratory assistance, which translates to increased airway pressure. ${ }^{(2)}$

In NAVA mode, inspiratory support is proportional to Edi, which is estimated by an esophageal catheter inserted through the subject's nose specifically for 
the application of NAVA. In PAV mode and, more specifically, in its latest commercial version, PAV+, inspiratory support is delivered in proportion to the work of breathing performed by the patient, estimated by applying end-inspiratory micropauses that allow estimation of the resistance and static elastance of the respiratory system by using the equation of motion. ${ }^{(40)}$

In NAVA mode, after positioning of the catheter, Edi is measured breath by breath and used for triggering, to deliver inspiratory support in proportion to patient effort, and for cycling. Triggering occurs when Edi increases by $0.5 \mu \mathrm{V}$ above baseline activity, and cycling occurs when Edi decreases to $70 \%$ of its peak. The inspiratory support delivered by the ventilator is adjusted by the NAVA level, or NAVA gain, a factor by which Edi is multiplied to determine the pressure that will be applied to the airways. ${ }^{(41)}$ Therefore, patient effort, estimated by the Edi waveform, determines triggering, pressurization, and cycling in NAVA, and the only parameter that has to be set by the clinician is the NAVA level. For instance, if the NAVA level is set to $2 \mathrm{cmH}_{2} \mathrm{O} / \mu \mathrm{V}$, and if, in a given breath, peak Edi is $10 \mu \mathrm{V}$, peak airway pressure will be $10 \times 2$, that is, $20 \mathrm{cmH}_{2} \mathrm{O}$.

In $\mathrm{PAV}+$ mode, once respiratory system elastance and airway resistance have been estimated, the ventilator measures instantaneous inspiratory flow and volume and uses the equation of movement to determine the pressure that will be applied to the airways. Therefore, the percentage of the total work of breathing that will be performed by the ventilator is adjusted, and the ventilator delivers inspiratory flow in proportion to patient effort to perform the determined percentage of the total work of breathing. In addition, the ventilator continuously displays the work of breathing performed by the patient, breath by breath, thereby guiding the adjustment of the percentage of assistance delivered. ${ }^{(39,40)}$ For instance, if inspiratory support is set to $60 \%$ of the total work of breathing and the patient is performing a low work of breathing, the percentage of assistance should be reduced until the work of breathing performed by the patient is within an appropriate range, which not only prevents over assistance but also prevents fatigue. Cycling in PAV+ mode is flow based and is set to an absolute value, usually being preset at $3 \mathrm{~L} / \mathrm{min}$.

NAVA and PAV reduce patient-ventilator asynchrony when compared with PSV. ${ }^{(39,40)}$ NAVA is particularly effective in reducing trigger asynchrony, given that this type of asynchrony occurs when the ventilator detects the onset of Edi, and several studies have shown that NAVA reduces the incidence of ineffective efforts. ${ }^{(42-45)}$ In contrast, NAVA can increase the incidence of double triggering, and, therefore, the incidence of this type of asynchrony can be monitored during its use. ${ }^{(4,44,46)}$ The only clinical study that has evaluated clinical outcomes failed to show any superiority of NAVA over PSV(47) although there are other ongoing studies. PAV+ has also been compared with PSV, showing better patient control of tidal volume, better quality of sleep, and reduction of asynchrony events. ${ }^{(8,48-50)} \mathrm{PAV}+$ can be used in COPD patients experiencing asynchrony during PSV, as long as care is taken to avoid leaks, which can lead to errors in estimating elastance and resistance, impairing the proper functioning of PAV+. (2)

Single-circuit ventilators or ventilators originally designed for noninvasive ventilation have flow generators and use a single circuit for inspiration and expiration, with exhalation holes in the circuit, which is open to the environment. They use automatic trigger and cycle algorithms and interact well with patients; in addition, these devices appear to reduce auto-trigger asynchrony and to optimize trigger synchrony. ${ }^{(11)}$

\section{INNOVATIVE TECHNOLOGIES AND PROCESSES}

Two new approaches in the diagnosis and treatment of patient-ventilator asynchrony have gained prominence in recent years. The first one is the development of methods for the automatic detection of asynchrony. As previously discussed, the incidence of asynchrony is greatly underestimated, because bedside detection of asynchrony is poor. The sensitivity of residents and intensivists for detecting asynchrony by observing ventilator waveforms is usually low and is affected by their level of training. ${ }^{(7)}$ A study of health professionals found that specific training on MV improves the ability of these professionals to detect asynchrony on the basis of observation of waveforms on the mechanical ventilator display; however, this detection ability was not affected by length of experience or health professional type (nurse, physician, or physical therapist). ${ }^{(51)}$ Therefore, the development of automatic detection methods could improve the diagnosis of asynchrony, inform health professionals, and potentially be used in the future to suggest ventilator adjustments or even to provide the basis for automation of ventilator adjustments. ${ }^{(52)}$ Several algorithms that can detect wasted efforts, double triggering, or asynchrony in general have been developed, but their bedside application is still restricted to research protocols. ${ }^{(52-56)}$ The algorithms for detecting wasted efforts, which are common in COPD patients, and double triggering, ${ }^{(20)}$ which can be harmful in ARDS patients, have been shown to be particularly accurate and comparable to offline detection based on ventilator waveforms, which is itself much superior to online detection, at the bedside.

Another approach is the use of strategies of minimal or no sedation for patients with asynchrony, as discussed previously. These strategies have yet to be tested in larger clinical trials because they affect various domains of critically ill patients on MV. It is of note that, in our experience, i.v. fentanyl, especially when administered continuously and for a long time for the purposes of analgesia and sedation, can cause generalized muscle stiffness, an adverse effect that can lead to difficult-to-resolve asynchronies. 


\section{TRAINING HEALTH PROFESSIONALS IN THE DIAGNOSIS AND TREATMENT OF PATIENT-VENTILATOR ASYNCHRONY}

The provision of education on MV is considered insufficient given the needs of clinical practice. This is due to the lack of a specific curricular approach to the subject for physicians and health professionals during their education. ${ }^{(57,58)}$ In a study conducted in Brazil, ${ }^{(57)}$ medical students, residents, and emergency physicians considered their knowledge of MV management to be inadequate, according to data from a self-assessment tool. This implies a need for educational programs and training on MV for medical students and even for experienced physicians. ${ }^{(57)}$ Although training in MV is essential for the diagnosis of asynchrony, practical education on MV still requires further dissemination and a systematized approach. ${ }^{(51)}$ Logistical problems; limited space in ICUs and emergency rooms; limited clinical settings; potential risks to patients, faculty, and students; and difficulties in performing arterial blood gas analysis and imaging tests and analyzing their results are some of the obstacles found in MV education. ${ }^{(59,60)}$ Therefore, educational programs and training specifically addressing MV, based on realistic or virtual online simulation, are considered promising tools, but, to that end, studies and technological development are needed. ${ }^{(59,60)}$

\section{FINAL CONSIDERATIONS}

The most common types of patient-ventilator asynchrony are those related to triggering, such as ineffective effort, auto-triggering, and double triggering; those related to premature or delayed cycling; are those related to insufficient or excessive flow. Because patient-ventilator asynchrony is a common phenomenon and is associated with negative clinical outcomes in patients on MV, it is essential that ICU staff actively seek the diagnosis and prompt resolution of this problem. New ventilatory modes, such as NAVA and $\mathrm{PAV}+$, as well as software for automated detection and quantification of asynchronies, have shown promise but have yet to be made more accessible. Training programs addressing patient-ventilator asynchrony in MV should be stimulated and disseminated on a large scale.

\section{ACKNOWLEDGMENTS}

We thank postgraduate student Juliana Arcanjo Lino for her contribution. We also thank Xlung for granting access to their platform (www.xlung.net) for digital simulation of MV waveforms.

\section{REFERENCES}

1. Wunsch H, Linde-Zwirble WT, Angus DC, Hartman ME, Milbrandt EB, Kahn JM. The epidemiology of mechanical ventilation use in the United States. Crit Care Med. 2010;38(10):1947-53. https://doi. org/10.1097/CCM.0b013e3181 ef4460

2. Barbas CS, Isola AM, Farias AM, Cavalcanti $A B$, Gama AM, Duarte $A C$, et al. Brazilian recommendations of mechanical ventilation 2013. Part I. Rev Bras Ter Intensiva. 2014;26(2):89-121. https://doi. org/10.5935/0103-507X.20140017

3. Vasconcelos Rdos S, Melo LH, Sales RP, Marinho LS, Deulefeu $\mathrm{FC}$, Reis RC, et al. Effect of an automatic triggering and cycling system on comfort and patient-ventilator synchrony during pressure support ventilation. Respiration. 2013;86(6):497-503. https://doi. org/10.1159/000353256

4. Chao DC, Scheinhorn DJ, Stearn-Hassenpflug M. Patient-ventilator trigger asynchrony in prolonged mechanical ventilation. Chest. 1997;112(6):1592-9. https://doi.org/10.1378/chest.112.6.1592

5. Thille AW, Rodriguez P, Cabello B, Lellouche F, Brochard L. Patientventilator asynchrony during assisted mechanical ventilation. Intensive Care Med. 2006;32(10):1515-22. https://doi.org/10.1007/ s00134-006-0301-8

6. de Wit M, Pedram S, Best AM, Epstein SK. Observational study of patient-ventilator asynchrony and relationship to sedation level. J Crit Care. 2009;24(1):74-80. https://doi.org/10.1016/j.jcrc.2008.08.011

7. Colombo D, Cammarota G, Alemani M, Carenzo L, Barra FL, Vaschetto $\mathrm{R}$, et al. Efficacy of ventilator waveforms observation in detecting patient-ventilator asynchrony. Crit Care Med. 2011;39(11):2452-7. https://doi.org/10.1097/CCM.0b013e318225753c

8. Alexopoulou C, Kondili E, Plataki M, Georgopoulos D. Patientventilator synchrony and sleep quality with proportional assist and pressure support ventilation. Intensive Care Med. 2013;39(6):1040-7. https://doi.org/10.1007/s00134-013-2850-y

9. Branson RD. Patient-ventilator interaction: the last 40 years. Respir Care. 2011;56(1):15-24. https://doi.org/10.4187/respcare.00937

10. Nava S, Bruschi C, Fracchia C, Braschi A, Rubini F. Patient-ventilator interaction and inspiratory effort during pressure support ventilation in patients with different pathologies. Eur Respir J. 1997;10(1):17783. https://doi.org/10.1183/09031936.97.10010177

11. Vasconcelos RS, Sales RP, Melo LHP, Marinho LS, Bastos VP, Nogueira ADN, et al. Influences of Duration of Inspiratory Effort,
Respiratory Mechanics, and Ventilator Type on Asynchrony With Pressure Support and Proportional Assist Ventilation. Respir Care. 2017;62(5):550-557. https://doi.org/10.4187/respcare.05025

12. Ferreira JC, Chipman DW, Hill NS, Kacmarek RM. Bilevel vs ICU ventilators providing noninvasive ventilation: effect of system leaks: a COPD lung model comparison. Chest. 2009;136(2):448-456. https://doi.org/10.1378/chest.08-3018

13. Jubran A, Van de Graaff WB, Tobin MJ. Variability of patient-ventilator interaction with pressure support ventilation in patients with chronic obstructive pulmonary disease. Am J Respir Crit Care Med. 1995;152(1):129-36. https://doi.org/10.1164/ajrccm.152.1.7599811

14. Pohlman MC, McCallister KE, Schweickert WD, Pohlman AS, Nigos CP, Krishnan JA, et al. Excessive tidal volume from breath stacking during lung-protective ventilation for acute lung injury. Crit Care Med. 2008:36(11):3019-23. https://doi.org/10.1097/ CCM.0b013e31818b308b

15. Slutsky AS, Ranieri VM. Ventilator-induced lung injury. N Engl J Med. 2013;369(22):2126-36. https://doi.org/10.1056/NEJMra1208707

16. Nava S, Bruschi C, Rubini F, Palo A, lotti G, Braschi A. Respiratory response and inspiratory effort during pressure support ventilation in COPD patients. Intensive Care Med. 1995;21(11):871-9. https://doi. org/10.1007/BF01712327

17. Marini JJ, Rodriguez RM, Lamb V. The inspiratory workload of patientinitiated mechanical ventilation. Am Rev Respir Dis. 1986;134(5):9029. https://doi.org/10.1164/arrd.1986.134.5.902

18. Maclntyre NR, McConnell R, Cheng KC, Sane A. Patient-ventilator flow dyssynchrony: flow-limited versus pressure-limited breaths. Crit Care Med. 1997;25(10):1671-7. https://doi.org/10.1097/00003246$199710000-00016$

19. Akoumianaki E, Lyazidi A, Rey N, Matamis D, Perez-Martinez N Giraud $R$, et al. Mechanical ventilation-induced reverse-triggered breaths: A frequently unrecognized form of neuromechanical coupling. Chest. 2013;143(4):927-938. https://doi.org/10.1378/ chest.12-1817

20. Beitler JR, Sands SA, Loring SH, Owens RL, Malhotra A, Spragg $R G$, et al. Quantifying unintended exposure to high tidal volumes from breath stacking dyssynchrony in ARDS: the BREATHE criteria. Intensive Care Med. 2016;42(9):1427-36. https://doi.org/10.1007/ s00134-016-4423-3 
21. Yonis $H$, Gobert $F$, Tapponnier $R$, Guérin $C$. Reverse triggering in a patient with ARDS. Intensive Care Med. 2015;41(9):1711-2. https:// doi.org/10.1007/s00134-015-3702-8

22. Blanch L, Villagra A, Sales B, Montanya J, Lucangelo U, Luján M et al. Asynchronies during mechanical ventilation are associated with mortality. Intensive Care Med. 2015;41(4):633-41. https://doi. org/10.1007/s00134-015-3692-6

23. Gilstrap D, Maclntyre N. Patient-ventilator interactions. Implications for clinical management. Am J Respir Crit Care Med. 2013;188(9):1058-68. https://doi.org/10.1164/rccm.201212-2214Cl

24. Schmidt M, Demoule A, Polito A, Porchet R, Aboab J, Siami S et al. Dyspnea in mechanically ventilated critically ill patients. Crit Care Med. 2011;39(9):2059-65. https://doi.org/10.1097/ CCM.0b013e31821e8779

25. Liotti M, Brannan S, Egan G, Shade R, Madden L, Abplanalp B, et al Brain responses associated with consciousness of breathlessness (air hunger). Proc Natl Acad Sci USA. 2001;98(4):2035-40. https://doi. org/10.1073/pnas.98.4.2035

26. Yonis $H$, Crognier L, Conil JM, Serres I, Rouget A, Virtos M, et al. Patient-ventilator synchrony in Neurally Adjusted Ventilatory Assist (NAVA) and Pressure Support Ventilation (PSV): a prospective observational study. BMC Anesthesiol. 2015;15:117. https://doi. org/10.1186/s12871-015-0091-z

27. Branson RD, Blakeman TC, Robinson BR. Asynchrony and dyspnea. Respir Care. 2013;58(6):973-89. https://doi.org/10.4187/ respcare.02507

28. Sieck GC, Ferreira LF, Reid MB, Mantilla CB. Mechanical properties of respiratory muscles. Compr Physiol. 2013;3(4):1553-67. https:// doi.org/10.1002/cphy.c130003

29. Murias G, Lucangelo U, Blanch L. Patient-ventilator asynchrony Curr Opin Crit Care. 2016;22(1):53-9. https://doi.org/10.1097/ MCC. 0000000000000270

30. Mellott KG, Grap MJ, Munro CL, Sessler CN, Wetzel PA, Nilsestuen JO, et al. Patient ventilator asynchrony in critically ill adults: frequency and types. Heart Lung. 2014;43(3):231-43. https://doi.org/10.1016/j. hrtlng.2014.02.002

31. Vaschetto R, Cammarota G, Colombo D, Longhini F, Grossi F Giovanniello $A$, et al. Effects of propofol on patient-ventilator synchrony and interaction during pressure support ventilation and neurally adjusted ventilatory assist. Crit Care Med. 2014;42(1):74-82 https://doi.org/10.1097/CCM.0b013e31829e53dc

32. de Wit M, Miller KB, Green DA, Ostman HE, Gennings C, Epstein SK. Ineffective triggering predicts increased duration of mechanical ventilation. Crit Care Med. 2009;37(10):2740-5

33. Conti G, Ranieri VM, Costa R, Garratt C, Wighton A, Spinazzola G, et al. Effects of dexmedetomidine and propofol on patient-ventilato interaction in difficult-to-wean, mechanically ventilated patients: a prospective, open-label, randomised, multicentre study. Crit Care. 2016;20(1):206. https://doi.org/10.1186/s13054-016-1386-2

34. Chanques G, Kress JP, Pohlman A, Patel S, Poston J, Jaber S, et al. Impact of ventilator adjustment and sedation-analgesia practices on severe asynchrony in patients ventilated in assist-control mode. Crit Care Med. 2013;41(9):2177-87. https://doi.org/10.1097/ CCM.0b013e31828c2d7a

35. Drouot $X$, Bridoux A, Thille AW, Roche-Campo F, Cordoba-Izquierdo $A$, Katsahian $S$, et al. Sleep continuity: a new metric to quantify disrupted hypnograms in non-sedated intensive care unit patients. Crit Care. 2014;18(6):628. https://doi.org/10.1186/s13054-014-06284

36. Rittayamai N, Wilcox E, Drouot X, Mehta S, Goffi A, Brochard L. Positive and negative effects of mechanical ventilation on sleep in the ICU: a review with clinical recommendations. Intensive Care Med. 2016;42(4):531-541. https://doi.org/10.1007/s00134-015-41791

37. Dres M, Rittayamai N, Brochard L. Monitoring patient-ventilator asynchrony. Curr Opin Crit Care. 2016;22(3):246-53. https://doi. org/10.1097/MCC.0000000000000307

38. Roche-Campo F, Thille AW, Drouot X, Galia F, Margarit L, CórdobaIzquierdo $A$, et al. Comparison of sleep quality with mechanical versus spontaneous ventilation during weaning of critically II tracheostomized patients. Crit Care Med. 2013;41(7):1637-44 https://doi.org/10.1097/CCM.0b013e318287f569

39. Gilstrap D, Davies J. Patient-Ventilator Interactions. Clin Chest Med 2016;37(4):669-681. https://doi.org/10.1016/J.ccm.2016.07.007

40. Kacmarek RM. Proportional assist ventilation and neurally adjusted ventilatory assist. Respir Care. 2011;56(2):140-8; discussion 149-52. https://doi.org/10.4187/respcare.01021

41. Terzi N, Piquilloud L, Rozé $H$, Mercat A, Lofaso F, Delisle S, et al Clinical review: Update on neurally adjusted ventilatory assist-report of a round-table conference. Crit Care. 2012;16(3):225. https://doi. org/10.1186/cc11297

42. Piquilloud L, Vignaux L, Bialais E, Roeseler J, Sottiaux T, Laterre PF, et al. Neurally adjusted ventilatory assist improves patient-ventilator interaction. Intensive Care Med. 2011;37(2):263-71. https://doi. org/10.1007/s00134-010-2052-9

43. Spahija J, de Marchie M, Albert M, Bellemare P, Delisle S, Beck J, et al Patient-ventilator interaction during pressure support ventilation and neurally adjusted ventilatory assist. Crit Care Med. 2010;38(2):518 26. https://doi.org/10.1097/CCM.0b013e3181cb0d7b

44. Terzi N, Pelieu I, Guittet L, Ramakers M, Seguin A, Daubin C, et al. Neurally adjusted ventilatory assist in patients recovering spontaneous breathing after acute respiratory distress syndrome: physiological evaluation. Crit Care Med. 2010;38(9):1830-7. https:// doi.org/10.1097/CCM.0b013e3181eb3c51

45. Colombo D, Cammarota G, Bergamaschi V, De Lucia M, Corte FD, Navalesi P. Physiologic response to varying levels of pressure support and neurally adjusted ventilatory assist in patients with acute respiratory failure. Intensive Care Med. 2008;34(11):2010-8. https:// doi.org/10.1007/s00134-008-1208-3

46. Barbas CS, Ísola AM, De Farias AM, Cavalcanti AB, Gama AM Duarte $A C$, et al. Brazilian recommendations of mechanica ventilation 2013. Part 2. Rev Bras Ter Intensiva. 2014;26(3):215-39. https://doi.org/10.5935/0103-507X.20140034

47. Demoule A, Clavel M, Rolland-Debord C, Perbet S, Terzi N Kouatchet $A$, et al. Neurally adjusted ventilatory assist as an alternative to pressure support ventilation in adults: a French multicentre randomized trial. Intensive Care Med. 2016;42(11):17231732. https://doi.org/10.1007/s00134-016-4447-8

48. Xirouchaki N, Kondili E, Vaporidi K, Xirouchakis G, Klimathianaki M, Gavriilidis $\mathrm{G}$, et al. Proportional assist ventilation with load-adjustable gain factors in critically ill patients: comparison with pressure support. Intensive Care Med. 2008;34(11):2026-34. https://doi. org/10.1007/s00134-008-1209-2

49. Costa R, Spinazzola G, Cipriani F, Ferrone G, Festa O, Arcangeli A et al. A physiologic comparison of proportional assist ventilation with load-adjustable gain factors (PAV+) versus pressure support ventilation (PSV). Intensive Care Med. 2011;37(9):1494-500. https:// doi.org/10.1007/s00134-011-2297-y

50. Kondili E, Prinianakis G, Alexopoulou C, Vakouti E, Klimathianak M, Georgopoulos D. Respiratory load compensation during mechanical ventilation--proportional assist ventilation with loadadjustable gain factors versus pressure support. Intensive Care Med. 2006;32(5):692-9. https://doi.org/10.1007/s00134-006-0110-0

51. Ramirez II, Arellano DH, Adasme RS, Landeros JM, Salinas FA, Vargas AG, et al. Ability of ICU Health-Care Professionals to Identify Patient-Ventilator Asynchrony Using Waveform Analysis. Respir Care. 2017;62(2):144-149. https://doi.org/10.4187/respcare.04750

52. Piquilloud $L$, Jolliet $P$, Revelly JP. Automated detection of patient-ventilator asynchrony: new tool or new toy? Crit Care. 2013;17(6):1015. https://doi.org/10.1186/cc13122

53. Nguyen QT, Pastor D, Lellouche F, L'her E. Mechanical ventilation system monitoring: automatic detection of dynamic hyperinflation and asynchrony. Conf Proc IEEE Eng Med Biol Soc. 2013;2013:520710.

54. Gutierrez G, Ballarino GJ, Turkan H, Abril J, De La Cruz L, Edsall C, et al. Automatic detection of patient-ventilator asynchrony by spectral analysis of airway flow. Crit Care. 2011;15(4):R167. https://doi. org/10.1186/cc10309

55. Sinderby C, Liu S, Colombo D, Camarotta G, Slutsky AS, Navales $P$, et al. An automated and standardized neural index to quantify patient-ventilator interaction. Crit Care. 2013;17(5):R239. https://doi. org/10.1186/cc13063

56. Blanch L, Sales B, Montanya J, Lucangelo U, Garcia-Esquirol O, Villagra $A$, et al. Validation of the Better Care $\AA$ system to detect ineffective efforts during expiration in mechanically ventilated patients: a pilot study. Intensive Care Med. 2012;38(5):772-80. https://doi.org/10.1007/s00134-012-2493-4

57. Tallo FS, de Campos Vieira Abib S, de Andrade Negri AJ, Cesar P Lopes RD, Lopes AC. Evaluation of self-perception of mechanical ventilation knowledge among Brazilian final-year medical students, residents and emergency physicians. Clinics (Sao Paulo). 
2017;72(2):65-70. https://doi.org/10.6061/clinics/2017(02)0

58. Heisler M. Hospitalists and intensivists: partners in caring for the critically ill-the time has come. J Hosp Med. 2010;5(1):1-3. https:// doi.org/10.1002/jhm.580

59. Lino JA, Gomes GC, Sousa ND, Carvalho AK, Diniz ME, Viana Junior AB, et al. A Critical Review of Mechanical Ventilation Virtual
Simulators: Is It Time to Use Them? JMIR Med Educ. 2016;2(1):e8. https://doi.org/10.2196/mededu.5350

60. Lynch-Smith D, Thompson CL, Pickering RG, Wan JY. Education on Patient-Ventilator Synchrony, Clinicians' Knowledge Level, and Duration of Mechanical Ventilation. Am J Crit Care. 2016;25(6):545551. https://doi.org/10.4037/ajcc2016623 


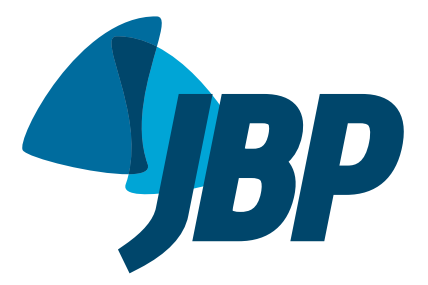

Artigo: Patient-ventilator asynchrony.

Publicação: J. bras. pneumol., ahead of print Epub 16-Jul-2018.

DOI: http://dx.doi.org/10.1590/s1806-37562017000000185

On page 3 , where is written:

"In PSV, increase the cycling threshold percentage criterion, or decrease PS, or increase rise time"

\section{It should be read:}

"In PSV, increase the cycling threshold percentage criterion, or decrease PS, or decrease rise time"

\section{On page 3 , where is written:}

"In PCV and PSV, decrease applied pressure, decrease rise time"

\section{It should be read:}

"In PCV and PSV, decrease applied pressure, increase rise time"

On page 6, Figure 3, where is written:

"Pmus (cmH20): -10??????"

It should be read:

"Pmus (cmH20): -10" 